\title{
A Multimethodology for Supporting the Boundary Selection of System Dynamics Models
}

\author{
Leandro Duarte dos Santos, Federal University of Santa Catarina, Brazil \\ Sandro Luis Schlindwein, Federal University of Santa Catarina, Brazil \\ Erwin Hugo Ressel Filho, Universidade Regional de Blumenau, Brazil \\ (iD https://orcid.org/0000-0001-6274-5129 \\ Caroline Rodrigues Vaz, Federal University of Santa Catarina, Brazil \\ Mauricio Uriona Maldonado, Federal University of Santa Catarina, Brazil \\ (iD https://orcid.org/0000-0002-1174-4828 \\ Alfredo Celso Fantini, Federal University of Santa Catarina, Brazil \\ Mischel Carmen Neyra Belderrain, Instituto Tecnológico de Aeronáutica, Brazil
}

\begin{abstract}
System dynamics models can produce knowledge for decision makers and, consequently, provide better choices. To be effective in its purpose, a model must reproduce an observed problem situation effectively. Hence, the compatibility between the observed problem situation and the created model is essential and represents a considerable challenge. In this context, this paper aims to describe an adaptation of the problem structuring method, 'Strategic Options Development and Analysis' (SODA), used in the problem articulation (boundary selection) step of the system dynamics modelling process. In summary, this adaptation consists of (1) selecting of stakeholders; (2) capturing, aggregating, and interpreting the insights using cognitive and causal maps; and (3) using the interpretation of the causal maps for building a system dynamics model. The method proved to be satisfactory since it was able to direct the construction of a system dynamics model based on a problem situation perceived by stakeholders acting in the native forests of the state of Santa Catarina, Brazil.
\end{abstract}

\section{KEYWORDS}

Bull's Eye Diagram, Cognitive Maps, Conflicting Agenda, Decision-Making Process, Design of Policies, Group Model Building, Problem Structuring Methods, Strategic Options Development and Analysis

\section{INTRODUCTION}

Managing complex and dynamics problems is not an easy task. This difficulty emerges mainly from the non-capability of predicting unwanted negative consequences, which results from the decisionmaking process. However, the simulation of the dynamics of a problem situation, from mathematical models based on the System Dynamics approach, can generate knowledge about this situation, and 
consequently guide decisions with a systemic and dynamics feature, thus providing a greater probability of "correct" actions. (Vennix, 1996; Sterman, 2000; Meadows, 2008; Aslani et al., 2018; Omamo et al., 2018; Abdollahi \& Ebrahimi, 2019; Haddad \& Otayek, 2019; Zelinka \& Amadei, 2019; Kizito \& Semwanga, 2020; Santos et al., 2020).

The benefits provided by system dynamics models are linked to their correct constructions. One of the main requirements for the process of building these models is that they can effectively replicate the problem situation faced. Thus, it must be compatibility between the problem situation faced and the model (Vennix, 1996; Sterman, 2000).

One way to achieve this compliance is through the adoption of a modelling process supported by Group Model Building (Vennix, 1996). In short, Group Model Building consists of an approach in which a facilitator, with knowledge in system dynamics and assisted by a group of stakeholders, builds a system dynamics model able of replicating the dynamics of a problem situation faced by that group.

According to Vennix (1996), the Group Model Building approach requires the engagement of a stakeholder's group, demanding periodic face-to-face meetings. This kind of meeting may be impossible, specially, in the case of a conflicting agenda of the group members. Then, the following question arises: is it possible to create a system dynamics model that replicates the problem situation faced by a group of stakeholders without face-to-face meetings to provide Group Model Building sections?

Santos et al. (2019), proposed an adaptation of a Problem Structuring Method (PSM) that can be done without face-to-face meetings. These authors applied the PSM Strategic Option Development and Analysis, in a group of stakeholders of the native forest of Santa Catarina state, Brazil. The implementing carried out by Santos et al. (2019) was able to structure a problem situation without face-to-face meetings with all stakeholders. However, is this PSM able to support the modelling process of System Dynamics Models?

The affirmative answer to this question can be provided by this paper since its objective is to describe an adaptation of the Strategic Option Development and Analysis (SODA) designed to be used at the first step of the system dynamics modelling process, which is Problem Articulation (Boundary Selection). The adaptation of the SODA for the system dynamics modelling process can support setting the boundary for system dynamics models, thus providing a compatibilization between a problem situation faced and a system dynamics model, avoiding building the right model for the wrong problem.

We present below the basic elements for understanding the adapted PSM for the context of system dynamics modelling process. Initially, we show a brief description of the Modelled Problem Situation in which the adapted PSM was created. Next, we present a short explanation about both the traditional System Dynamics modelling process and Strategic Option Development and Analysis - SODA problem structuring method. After, the basic elements for understanding the Proposed Multimethodology is described. Then, we present an applying of the proposed multimethodology for the context of the native forest of Santa Catarina state, Brazil. Finally, we highlight some Final Considerations.

\section{MODELLED PROBLEM SITUATION}

Siminski (2009), in his study on the native forests of Santa Catarina - Brazil (figure 1), listed several negative aspects that the region's forests and their actors have faced in the recent decades. According to this author, these negative aspects mainly result from a forest management process that does not consider the complexity of ecological, economic and cultural relations that govern the environment of native Santa Catarina's forests. Also, Siminski (2009) pointed out the need for more comprehensive forest policies that take into account different actors' views. The author also made a draft (from a causality diagram) on the capacity that systemic approaches can help to clarify the relationships that drive the dynamics of the remaining native forests of Santa Catarina state. 


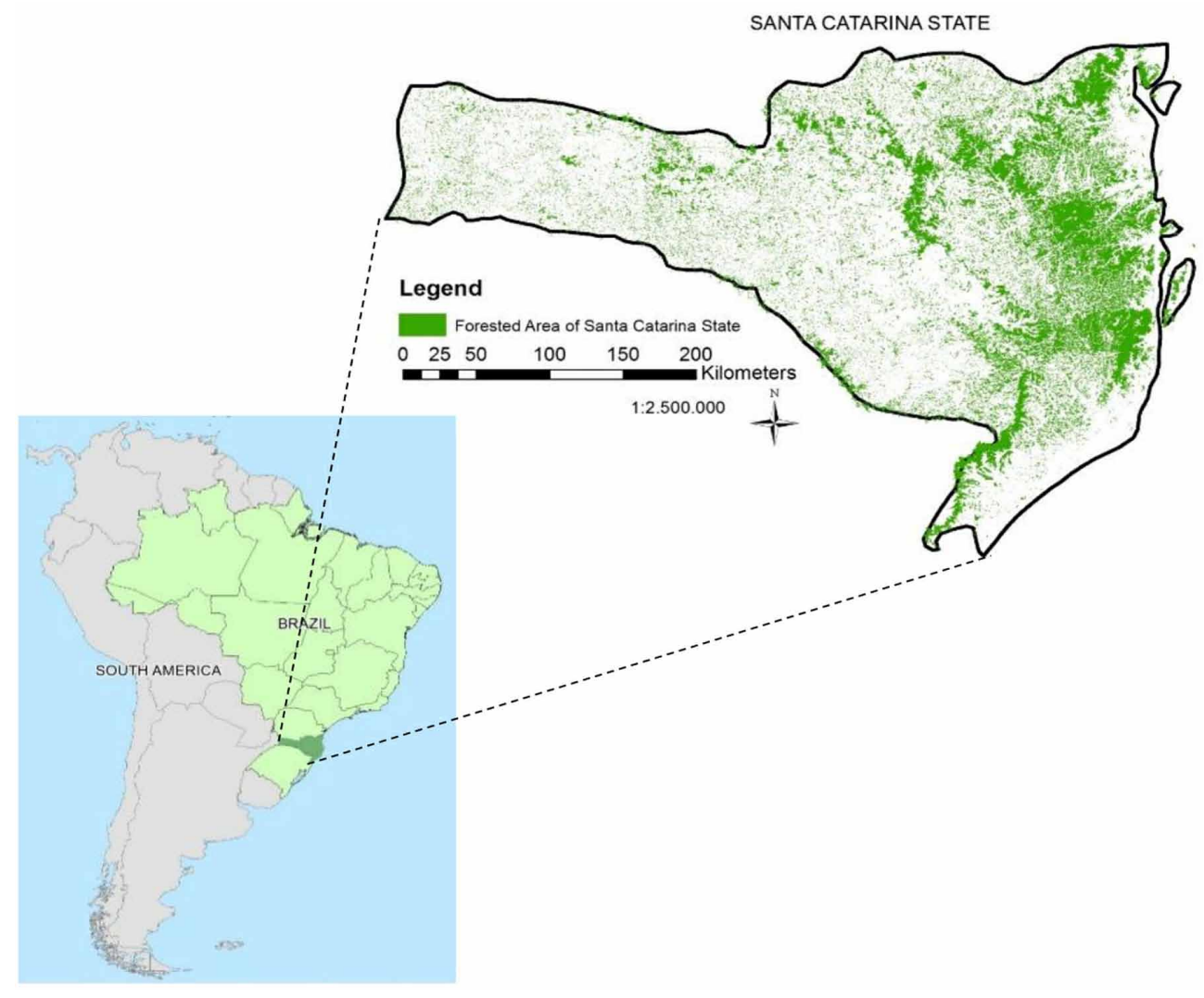

One of the systemic approaches that best fits to generate learning and consequently support the design of policies for the Santa Catarina's native forests is the Systems Dynamics. Model simulations based on this approach can dynamically replicate patterns resulting from the interaction between the elements that embrace this environment. Despite the capacity of system dynamics models to generate learning in dynamics situations, the requirement to consider different actors' views regarding the problem situation of Santa Catarina's native forests, raised by Siminski (2009), implies that the system dynamics modelling process must takes into account points of view (or insights) of different stakeholders. Therefore, at first, we thought, the modelling process should be supported by Group Model Building sections. However, the incapability to bring together at the same time, a stakeholders' group that represented different actors of the problem situation forced us to capture, aggregate and interpret the insights of this group from an adaptation of the SODA, which is able of both identifying and defining the problem to be modelled.

\section{SYSTEM DYNAMICS}

\section{Basic Aspects}

System dynamics is characterized as an approach and a set of conceptual tools that provide support to understand the structure and dynamics of complex systems. System Dynamics is also a rigorous modelling method that allows building computational simulations of complex systems, using them to design more effective policies and actions (Sterman, 2000; Meadows, 2008). System dynamics 
seeks to understand the structure and behaviour of systems composed by feedbacks links. For this purpose, this approach uses, mainly, two kinds of graphical notation: Causal Loop Diagrams and Stock and Flow Diagrams (Sterman, 2000).

Using Causal Loop Diagrams, it is possible to effectively understand the relationships among variables of a system, as well as to forecast the future, in case of any changes in the bounded variables. Thus, this tool helps the decision-making process of a problem situation and/or complex phenomenon that is occurring or will occur (Anderson \& Johnson, 1997). Figure 2 shows one example of Causal Loop Diagram.

In the causal loop diagram of Figure 2, the letter R describes the following information: "An increase in $\mathrm{x}$ leads to a higher level in $\mathrm{y}$, which in turn increases $\mathrm{x}$, and so on". Such behaviour characterizes a reinforcement feedback loop. The balance feedback in the same figure, evidenced by the letter B, can be interpreted as follows: "An increase in y leads to an increase in $\mathrm{z}$, which in turn decreases $y$ that reduces $z$ and increases $y$, and so on. Notwithstanding the relevance of this information, it is only possible to get a qualitative interpretation of the phenomenon represented by the Causal Loop Diagram.

Unlike the qualitative interpretation of Causal Loop Diagrams, the notation used to represent the stock and flow diagrams gives a physical interpretation of the system behaviour. Constants and variables are represented by circles, flows by double dash arrows that have a tap, stocks by rectangles, information by single dash arrows and external variables of the system by clouds (Sterman, 2000) (figure 3).

Figure 2. Example of Causal Loop Diagram, using Vensim ${ }^{\circledR}$ PLE software

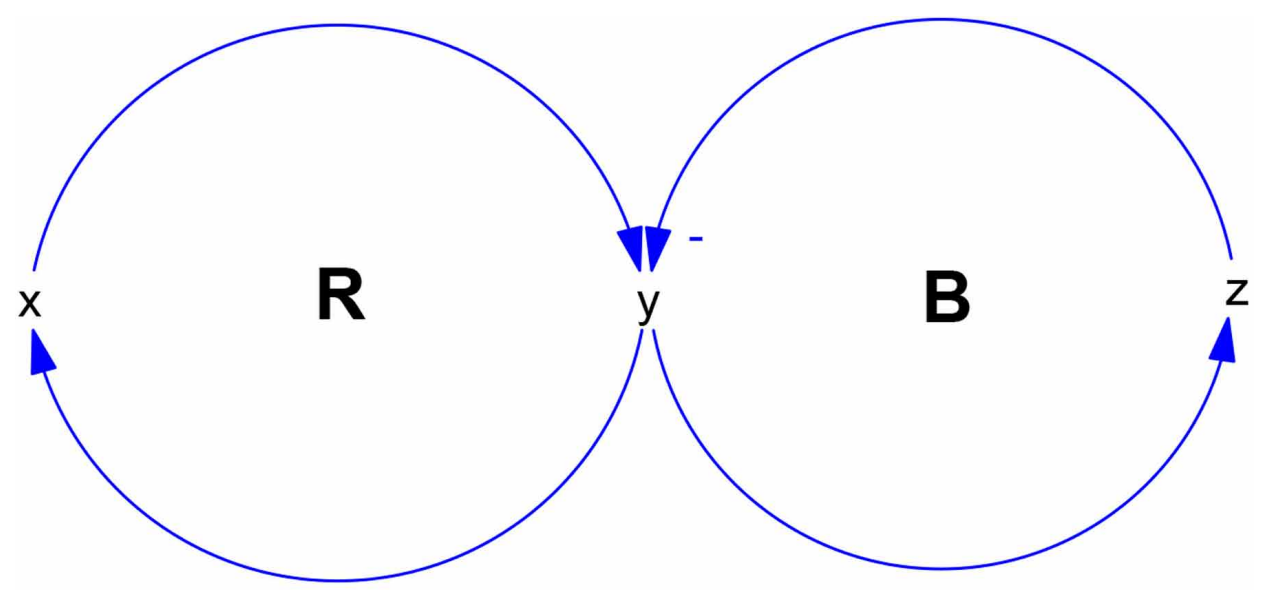

Figure 3. Example of stock and flow diagram, using STELLATM v9.0 software

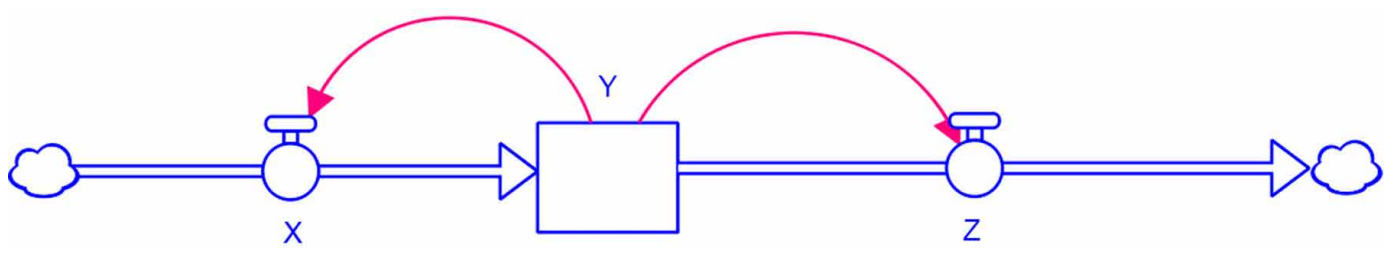


Mathematically, the flow and stock diagram in figure 3 can be represented as follows:

$Y(t)=\int_{t_{0}}^{t}[X(s)-Z(s)] d s+Y\left(t_{0}\right)$

where $\mathrm{X}(\mathrm{s})$ and $\mathrm{Z}(\mathrm{s})$ are, respectively, the inbound and outbound flow of stock at any time s between t0 and $t$.

The rate of change in stock can be gotten from the following equation:

$$
\frac{d(Y)}{d t}=\text { stock changerate }=X(s)-Z(s)
$$

\section{System Dynamics Modelling Process}

According to Sterman (2000), the system dynamics modelling is a feedback process, not a linear sequence of steps. Figure 4 shows a schema with the steps of the traditional system dynamics modelling process.

According to Sterman (2000), in step 1 of Problem Identification and Definition (Boundary Selection), basically occurs: (1) The selection of the theme that will be modelled; (2) the key variables that will be considered; (2) the timeline that will be portrayed, and the dynamic definition of the problem, that is, the determination of the historical behaviour of the concepts and key variables (reference modes).

In Step 2, Dynamic Hypothesis, the dynamic hypothesis is described, showing the endogenous behaviour of the modelled system. In this step, reference modes, key variables, and other available data are taking into account. The step 2 finishes with the graphical formulation of the model, which

Figure 4. Schema with the steps of the traditional System Dynamics modelling process, based on Sterman (2000)

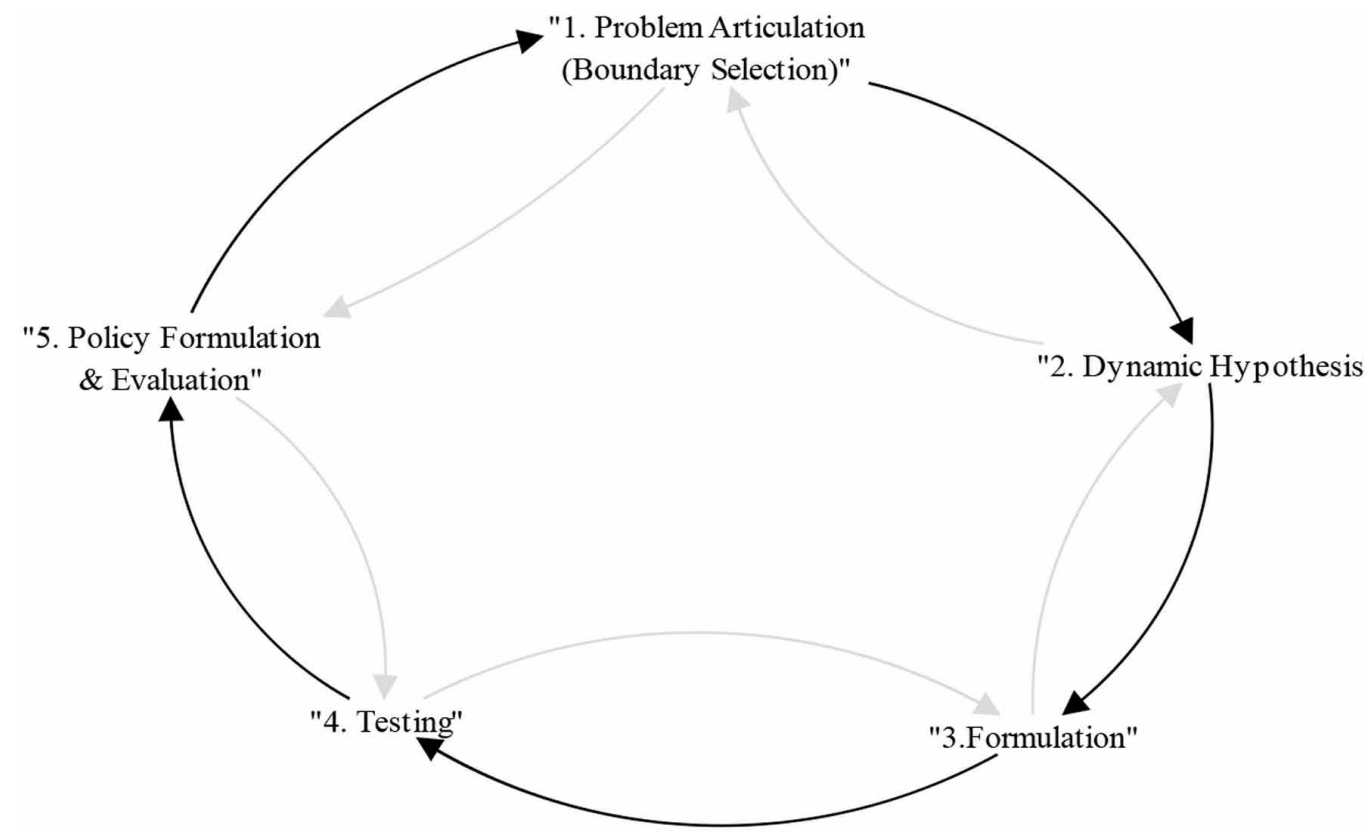


can be done by numerous tools, such as: causal loop diagrams, stock and flow diagrams, subsystem diagrams, structural policy diagrams, amongst others (Sterman, 2000).

In step 3, Model Construction (or according to Sterman (2000), Formulation of a Simulation Model), the structure and decision rules are specified, as well as the parameters estimation, behavioural relationships and initial conditions. At this stage, tests of consistency between what was initially proposed to be studied and the boundary of the model also takes place.

After the construction of the model, step 4, Simulation and analysis of the results is performed (Testing, according to Sterman (2000), in which the simulation results are compared with the preestablished reference modes, and robustness tests are also performed under extreme conditions, sensitivity, among others.

After the tests, in step 5, Policy Formulation \& Evaluation, it is possible to design and evaluate policies to improve the problem situation based on simulations carried out in the model, thus enabling thinking and acting systemically on the problem situation.

For more information on the steps in the dynamic modelling process see Sterman (2000, p.86).

\section{STRATEGIC OPTIONS DEVELOPMENT AND ANALYSIS - SODA}

\section{Theoretical Basis}

Strategic Options Development and Analysis - SODA is a method used for structuring problem situations, also widely used to support the strategy formulation process (Eden \& Ackermann, 2001; Ackermann \& Eden, 2010).

SODA uses cognitive maps to express the thoughts and opinions of groups engaged in problem situations, aiming to structure them as well as provide the establishment of strategies (Eden \& Ackermann, 2001; Ackermann \& Eden, 2010).

Cognitive maps are based on Kelly's theory (1955) and are characterized as graphical representations capable of systematically grouping cause-and-effect actions, situations or findings. Such maps, in the context of SODA, are based on the relationships that various constructs have with each other. A construct is characterized as a pair of antagonistic assertions, separated by three points, which express a certain action, situation or finding, ensuring that there are no ambiguous interpretations. Figure 5 presents the typical structure of a construct, in which antagonistic assertions are separated by three dots.

Figure 5. Example of a construct

\section{Knowledge about the dynamics and use of Native Forest resources ... Nonexistent or unprocessed data}


A cognitive map is composed of several interconnected constructs, following a hierarchical relationship of cause and consequence. The polarity of the constructs in these connections, signalled by signals, or the absence of them, at the tip of the arrows connecting the constructions, must be respected. Arrows with no signal or positive signal at the tip have a direct relationship, i.e. pole 1 of one construct with pole 1 of the other, and pole 2 of one construct with pole 2 of the other. The negative sign on the arrowhead presents an inverse polarity relation, i.e., the pole 1 of one construct with the pole 2 of the other, and vice-versa (Eden \& Ackermann, 2001; Ackermann \& Eden, 2010). To exemplify, Figure 6 shows a brief cognitive map that encompasses the causes and consequences of the construct representing in figure 5. Surely, the cognitive map of Figure 6 is extremely modest and has only the purpose of exemplifying the relationship of causes and consequences.

Cognitive maps are susceptible to perform a series of analyses. From these analyses, it is possible to obtain information regarding the importance of certain constructs in the context of a mapped problem situation.

\section{Map Analyses}

The analyses carried out in cognitive maps are based on the identification of constructs with privileged location on the map or with many connections, as portrayed in Figure 2, which shows the terminology of some constructs taking into account the number connections and relative position in the causal map.

The layout of the cognitive map exemplifies the hierarchy of constructs. At the top, constructs with long-term goals and objectives are found, whereas the lowest constructs characterize short-term actions. The constructs located on the top of the map are known as head constructs, which are probable candidates for representing the objectives of the interviewee group. They only receive links from constructs under located (Ackermann \& Eden, 2010; Eden \& Ackermann, 2001; Eden and Ackermann, 2013). The constructs just below the objectives are called strategic options, i.e. frequently long-term facts which can offer the materialization of the objectives (Georgiou, 2011; Georgiou, 2012).

Constructs assembled together with one particular strategic option are called clusters. This architecture is often in the form of a tear drop (see Figure 7). It is possible to find more than one cluster

\section{Figure 6. Example of a cognitive map}

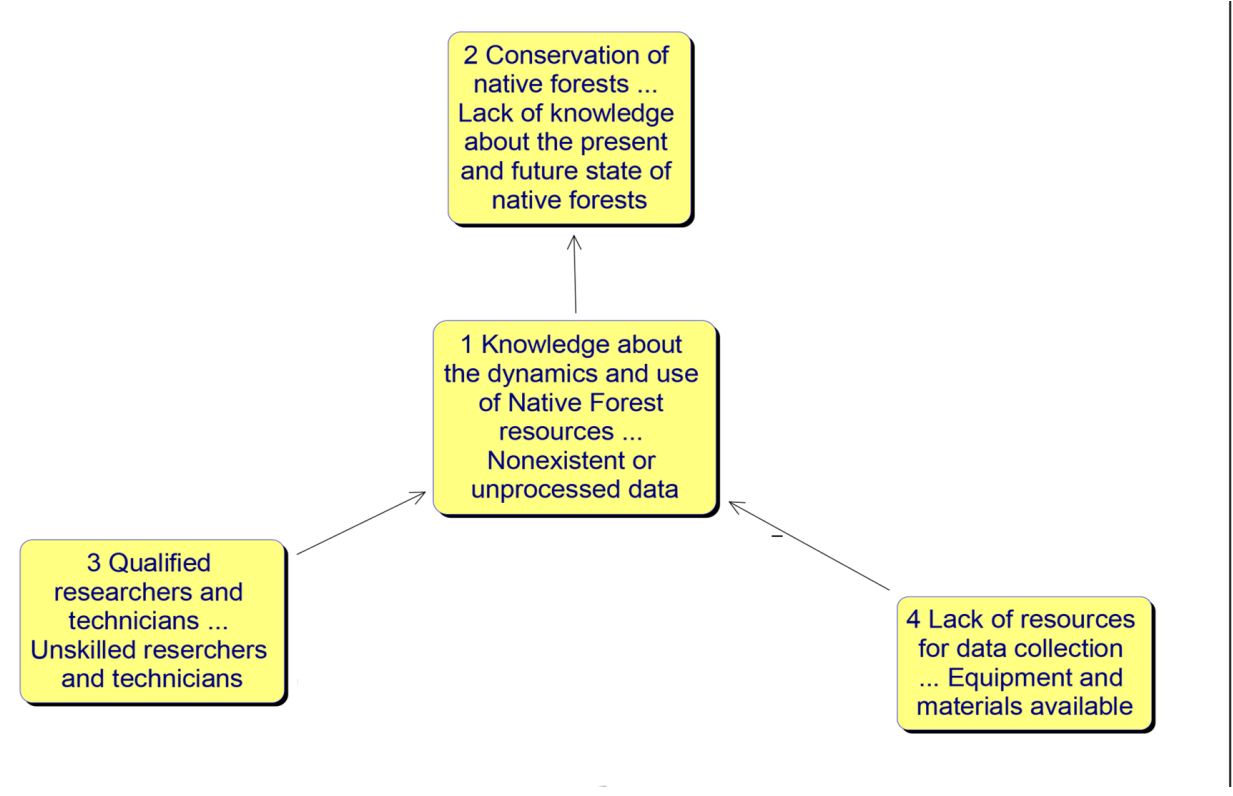




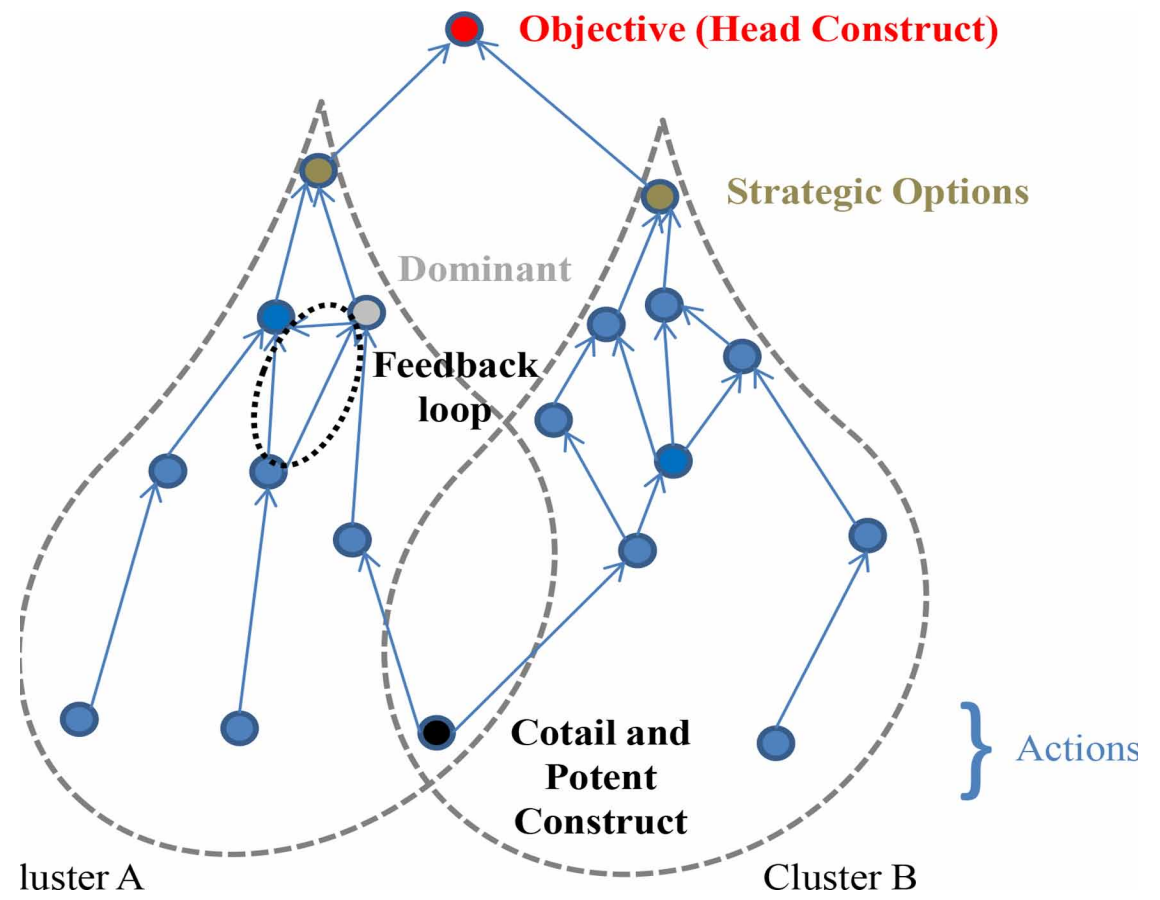

on the cognitive map. The separation of a map into clusters is recognized as cluster segmentation (Ackermann \& Eden, 2010; Eden \& Ackermann, 2001 Eden \& Ackermann 2013). If a construct belongs to more than one cluster, it is stated to as a 'potent construct', as it indicates its contribution to more than one strategic option. A potent construct is usually seen near or at the bottom of the cognitive map. A construct that is part of a cluster and contains more than one outbound link is known as a 'co-tail construct'. This, too, is usually located near or at the bottom of the map. If a construct has both the status of being potent and co-tail, it unavoidably has a higher potential to reach the construct that represents the objective (Ackermann \& Eden 2010, Eden \& Ackermann 2001, Eden \& Ackermann 2013).

One construct that has many links, either inbound or outbound, is identified as a 'dominant construct' and represents key issues in the problem situation (Ackermann \& Eden 2010, Eden \& Ackermann 2001, Eden \& Ackermann 2013).

A cognitive map may also have a circular or dynamic structure between two or more constructs, showing the occurrence of a feedback loop (Ackermann \& Eden 2010, Eden \& Ackermann 2001, Eden \& Ackermann 2013). In short, the map analyses aforementioned assist in providing a fast understanding of complex problem situations.

\section{Traditional Procedure For Applying SODA}

Usually, the SODA method is applying to structure a problem situation, faced by stakeholders, take into account the following steps (Banxia Software Ltd, 2017):

1. Individual interviews with each member of the group and elaboration of individual cognitive maps: Group members are interviewed separately by a facilitator, at which time the interviewee 
exposes the problem situation according to his/her point of view. Each interview is "translated" by the facilitator into an individual cognitive map;

2. Modelling and Analysis: considering each individual map, the facilitator merges each one into a general map, which is called causal map. This map is susceptible to be analysed, according to the map analyses discussed in the last subsection;

3. Group workshop: The facilitator organizes a workshop in which all or as many interviewees as possible can attend. During the workshop, the causal map is discussed among the participants and it may be modified;

4. Group decision support workshop: the causal map is shown to people who are involved in the problem situation. This workshop aims to generate knowledge and expose other points of view, regarding the problem situation, for the involved people. Another purpose of the workshop is to identify possible actions, from a negotiation process between the participants (intermediated by the facilitator); and

5. Monitoring, control and evaluation: the final causal map, which is the result of the group workshop, can be used to track and monitor the actions progress.

Although SODA has a "traditional" methodological procedure, it is an extremely flexible method and can have several configurations depending on the kind of problem situation, the customer's objective, the availability of the interviewees, the infrastructure, and the available technological apparatus. Variations of the method can be observed in Ackermann and Eden (2010) and Eden and Ackermann (1998). A good example of adaptation can be seen in Hjortso (2004), which carries out phases 1 and 2 of the method. In Hjortso's study, the results are presented in form of a catalogue to stakeholders. Bryson et al. (2004), discuss the possibility of using one adaptation of SODA method for structuring a problem situation based on the perception of only one stakeholder.

\section{MULTIMETHODOLOGY}

Despite the benefits that a single systemic methodology can provide to a research work or an intervention on a problem situation, several publications such as Mingers and Brocklesby (1997), Mingers and Rosenhead (2004), Mingers (2009) and Mingers (2010) point out that quality and robustness of works and/or interventions can be improved with the use of multi-methodologies.

To understand what multi-methodology is, at first, it is necessary to keep in mind the differences between the following concepts: paradigm, methodology and technique (Mingers \& Brocklesby, 1997):

- Paradigm: set of philosophical assumptions that define the nature of possible research and interventions. Regarding categorization, in terms of multi-methodology, there are three main paradigms: empirical-analytical (also known as positivist, objectivist, functionalist and hard), interpretive (subjectivist, constructivist and soft), and critical (critical systems);

- Methodology: a well-determined set of procedures or activities that help to obtain results in researches or interventions; and

- Technical: specific activity with a clear and well-defined purpose within the context of a given methodology.

Once the above concepts are presented, it is possible to define multi-methodology as the "art" of using together more than one methodology or part of methodologies (from the same paradigm or not), considering the positive aspects and limitations of the methodologies chosen to deal with a given problem situation (Mingers \& Brocklesby, 1997). This "art", or multi-methodological approach, is based on the principle that there is no one more appropriate methodology, but all methodologies have advantages and disadvantages that can be offset and grouped in the same research (Antoun Netto, 2012). 
According to Moran-Ellis et al. (2006), there are many justifications for adopting the multimethodological approach, among which the following ones stand out:

- Increased level of confidence and accuracy in results;

- Achievement of new findings by summarizing results from various approaches;

- Reconciliation of different constructions of the same phenomenon;

- Maximizing the possibilities of thinking on the complexity of phenomena; and

- Optimization of the logical implementation of a theoretical approach.

Despite the many advantages that emerge from the adoption of multi-methodological approaches, Mingers and Brocklesby (1997) draw attention to some philosophical, theoretical and practical problems that can arise from this adoption, especially if the grouped methodologies are of different paradigms. Philosophically, there is a possibility of paradigmatic incommensurability; theoretically, the effective fit of methodologies may not occur; and practically, the facilitator is required to be flexible and to know a wide range of knowledge and skills.

Although the disadvantages related to the use of multi-methodological approaches, the huge potential to generate knowledge about problem situations have been spreading the multimethodological approach, as can be observed in Howick and Ackermann (2011). Parallel to this spreading out, the range of multi-methodology configuration is increasing, among which Eden (1994), Willians et al. (1995), Vennix (1996), Ackermann et al. (1997), Eden (2004) and Howick et al. (2008) highlight the powerful combination that can result from the union between cognitive or causal maps and System Dynamics.

\section{THE PROPOSED MULTIMETHODOLOGY}

Considering the problem situation of native forests of Santa Catarina described in section 2, We proposed a Multimethodology. In this, step 1, Problem Identification and Definition (Boundary Selection), of the system dynamics modelling process is performed using an adaptation of the PSM Strategic Options Development and Analysis - SODA (Figure 8).

Figure 8. Schema of the proposed multimethodology

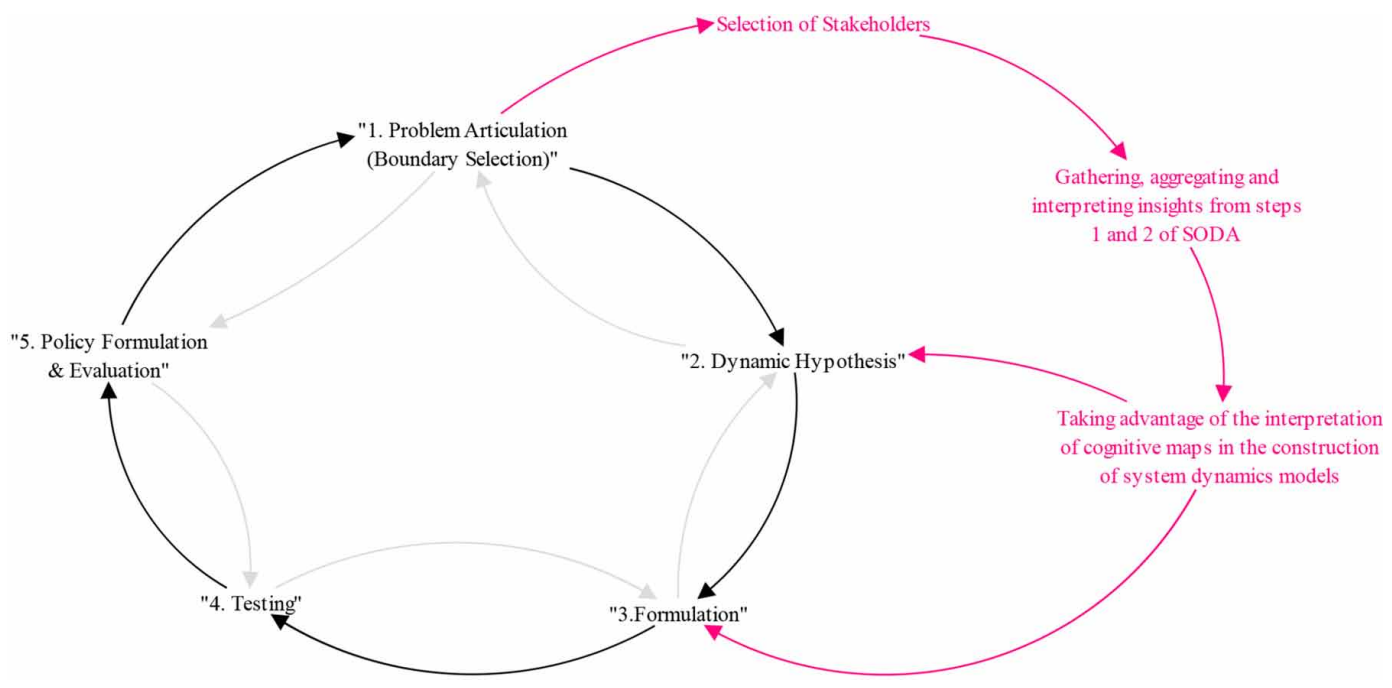


The adaptation of the SODA method consisted in carrying out its steps 1 and 2 in a pre-selected stakeholders' group. The results generated from the analyses performed on the causal map 1 provided relevant information for the steps 2 and 3 of the system dynamics modelling process. The application of the adapted SODA method and the adequacy of its results to the context of system dynamics modelling process was performed according to the following steps: (1) selection of stakeholders; (2) gathering, aggregating and interpreting insights from steps 1 and 2 of SODA; and (3) Taking advantage of the interpretation of cognitive maps in the construction of system dynamics models.

\section{Selection of Stakeholders}

The process of choosing stakeholders who would provide insights for the identification and definition of the problem situation was done in accordance with the "stakeholder power-interest grid" proposed by Ackermann and Eden (2011) (figure 9).

In addition to respecting the power-interest grid, the stakeholder's selection process also aimed to consider a huge diversity of organizations in the state of Santa Catarina that have a relation with the management of its forest resources. Thus, the group of interviewees would cover different perspectives, meeting the need raised by Siminski (2009).

After choosing the stakeholders, it was released that is impossible to bring together in a face-toface meeting all selected stakeholders, given the incompatibility of the participants' agendas. Despite the impossibility of gathering all stakeholders, we opted for their confirmation in the study, since those chosen would have a lot of insights about the problem situation. Thus, instead of adjusting the agenda of stakeholders for face-to-face Group Model Building sections, we adapted the SODA method to capture, aggregate and interpret stakeholders' insights.

\section{Gathering, Aggregating and Interpreting Insights From Steps 1 and 2 of Strategic Options Development and Analysis (SODA)}

The procedure chosen to capture, aggregate and interpret insights from the stakeholder group was an adaptation of the SODA problem structuring method, which is very similar to the method applied in Hjortso (2004). In Hjotso's research, steps 1 and 2 of the SODA were carried out. Basically, the

Figure 9. Outline of the stakeholder power-interest grid, based on Ackermann and Eden (2011)

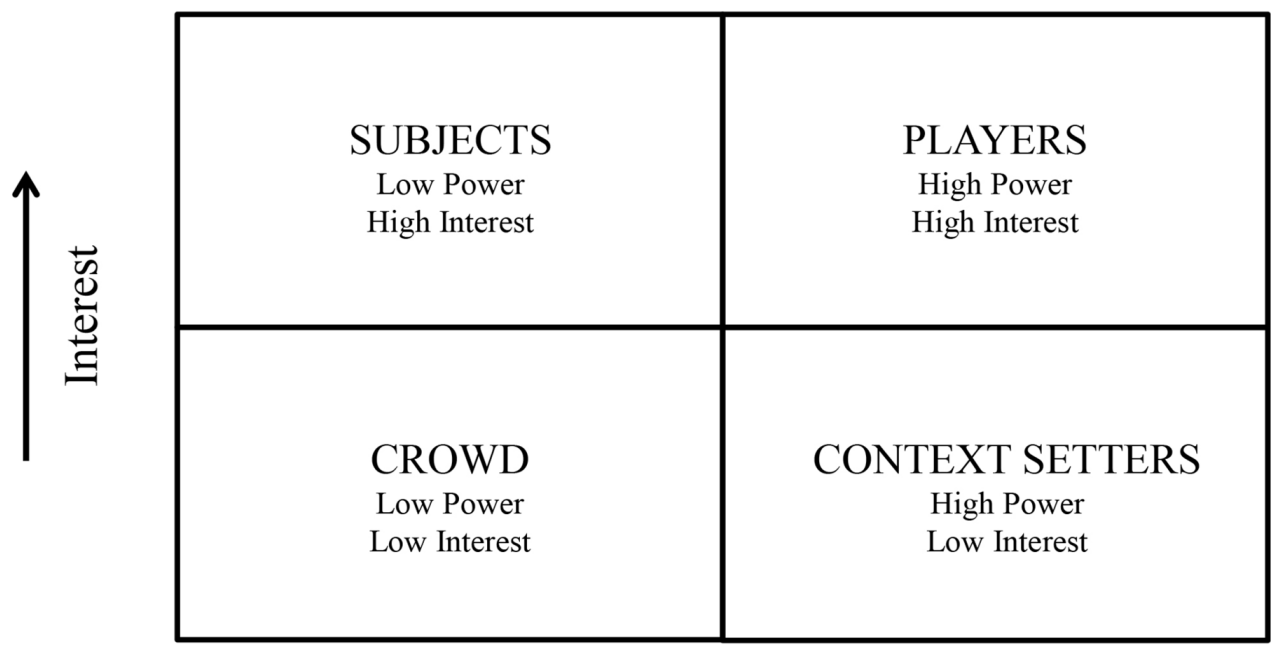

Power 
insights of each stakeholder were gathered in an individual interview, then, based on this interview, cognitive maps were built (step 1 of traditional SODA); aggregating the cognitive maps was a result of the merge process, which generated a general map, also called causal map, after the merge process, the causal map was validated by the interviewed group; the interpreting insight process was priori based on the map analyses described in subsection 4.2 (Step 2 of traditional SODA). The creation and aggregation of cognitive maps, as well as the interpretation of the map resulting from the merging process were performed in the Decision Explorer software. More details about the causal map and its analyses, which structure the problem situation of Santa Catarina native forests, can be seen in Santos et al. (2019).

After structuring the problem situation, and consequently identify and define the problem to be investigated by the system dynamics model, a new challenge was initiate for the facilitator, i.e., to define how to use such insights for in the system dynamics modelling process.

\section{Taking Advantage of The Interpretation of Cognitive Maps In The Construction of System Dynamics Models}

As mentioned in the previous subsection, the interpretation of cognitive maps can generate relevant information about a given problem situation, and consequently supports the system dynamics modelling process. The structural arrangement of these maps can provide evidences in order to build a model that embraces the stakeholders' perception of the problem situation. Next, considering the experience of building the model for the problem situation of native forests of Santa Catarina, we discuss how the structure, as well as the results of map analysis, can assist the system dynamics modelling process.

\section{Structuring Relationships and Analysis of Cognitive Maps Became System Dynamics Elements}

According to Ford (1999), bull's eye diagrams represent a tool that organize the variables that make up a given system dynamics model. These diagrams help to establish the boundary of a model, explaining which variables are part of the model, distinguishing them into exogenous (i.e., inputs) and endogenous (outputs). Figure 10 shows an example of a bull's eye diagram.

From the bull's eye diagram in Figure 10, it is possible to receive the following information: (1) the model is composed of variables a, b, c, d, e, f, g; (2) variables a, b and c are endogenous; (3) d, $\mathrm{e}, \mathrm{f}, \mathrm{g}$ are exogenous variables; and variables $\mathrm{h}, \mathrm{i}, \mathrm{j}$ are not part of the model.

The construction, aggregation and interpretation of cognitive maps can also inform the variables that may become a model, classifying them into endogenous and exogenous ones. Such similarity results mainly from the ability to aggregate similar variables that both cognitive maps and the bull's eye diagram have. This similarity can be easily visualized by superimposing a bull's eye diagram on the generic cognitive map shown in Figure 7 (figure 11).

The superposition of a generic cognitive map and a bull's eye diagram provides the following information that are relevant to the system dynamics modelling process:

- Constructs that do not receive links have great potential to be converted into exogenous variables (inputs) of the system dynamics model;

- Constructs that are not at the base of the map can have great potential to be converted into endogenous variables of the model;

- Constructs not mentioned by the stakeholders are less expected (in relation to those mentioned) to be converted into variables of the system dynamics model.

Besides the relationship between cognitive maps and bull's eye diagrams, constructs with some characteristics not yet mentioned can also give clues about the structuring of system dynamics models (steps 2 and 3 of the system dynamics modelling process): 
Figure 10. Example of bull's eye diagram, adapted from Ford (1999)

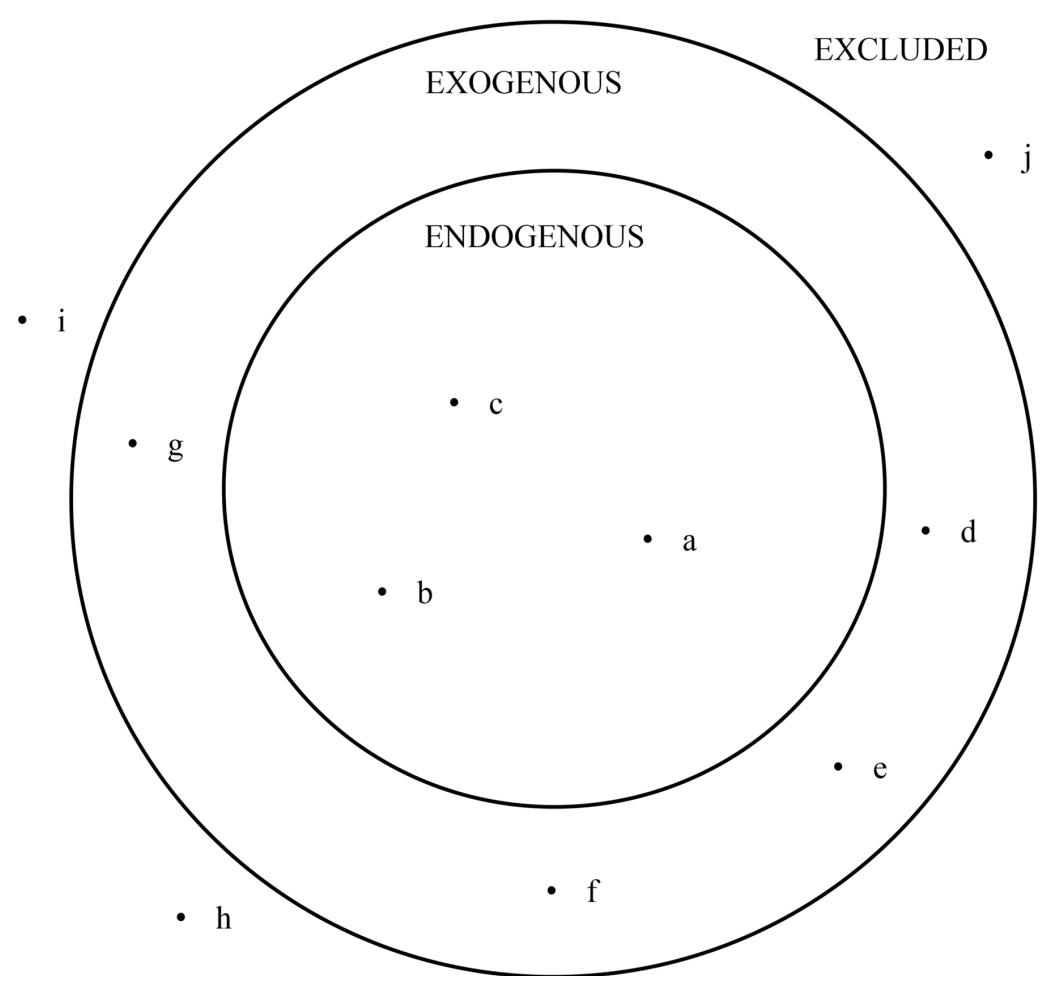

Figure 11. Relationship between bull's eye diagram and cognitive map structures

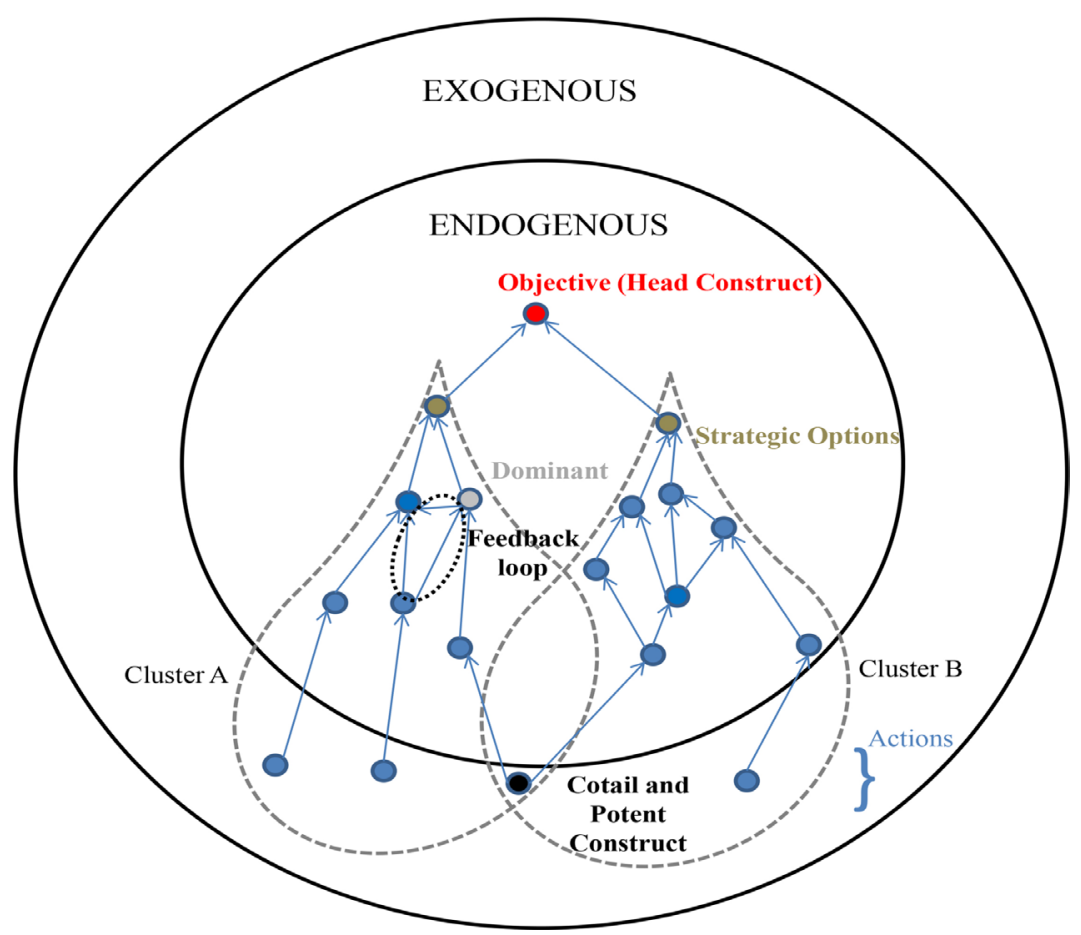


- Head constructs may be related with variables that represent the reference mode to be studied in the system dynamics model since they represent the objective of the structured problem situation;

- Clusters can represent sectors or subsystems in system dynamics models since these used to group constructs (or variables) corresponding to a given subject;

- The greater the number of connections of construction, the greater its relevance within the problem situation, and consequently, the greater the effort should be to include it in the system dynamics model;

- Interlinked constructs forming feedback loops can help, in a more direct way, the construction of Causal Loop Diagrams, as also mentioned in Eden (1994), Willians et al. (1995), Vennix (1996), Ackermann et al. (1997), Howick et al. (2008).

In spite of the relevance of the relationships aforementioned, which can provide clues of variables and possible connections that should be included in the model, they are essentially within a qualitative field. Considering that system dynamics models are quantitative, the following question arises: how to transform constructs and their links from qualitative character to variable arrangements with a quantitative character?

\section{Transforming Cognitive Maps Into System Dynamics Structures}

As a result of the relationships presented in the previous subsection, some constructs are highlighted to take part in system dynamics models. However, such inclusion should consider both the coherence of the argument line of the stakeholder group and a logical-structural sequencing of the system dynamics modelling process. For this, we suggest:

1. Assign units to constructions or clusters that have a similar meaning, thus turning them into variables;

2. Check the coherence between the links suggested by the stakeholders, i.e., are the units of the newly created variables make sense? (similar to performing a consistency test between units);

3. Reorganize the variables, that is, determine "what is a function of what" (in case of any variable does not have a direct relationship with any other, consider its exclusion or the inclusion of a variable that performs the non-existent connection).

4. Reorganize the variables respecting the dynamic structures of the existing system patterns (exponential growth, production curve, overshooting, etc.) taking into account the reference modes. If possible, consider the structure and results of cognitive map analyses to include variables into the model. For example, variables from tails constructs should be exogenous, variables from dominant constructs would be preferred to be included into the model, match the reference modes with variables from head constructs.

After showing the aforementioned procedures, we suggest following the system dynamics modelling process (presented in figure 4) from step 4.

\section{APPLYING THE PROPOSED MULTIMETHODOLOGY FOR THE CONTEXT OF THE FORESTS OF SANTA CATARINA - BRAZIL}

Applying the steps 1 and 2 of the SODA method in 8 stakeholders who are interested in the native forests of Santa Catarina state - Brazil, we obtained the causal map available in Santos et al. (2019) (figure 12). This map represents the structured problem situation, from the perspective of these stakeholders.

Using the procedures mentioned in this paper, which support the system dynamics modelling process, the boundary of the system and variables that should be taken part of the model were 
Figure 12. Causal map built according to Santos et al. (2019) In red: head constructs. In brown: strategic options. In gray: dominant constructs. In black: cotail and potent constructs. In blue: other constructs.

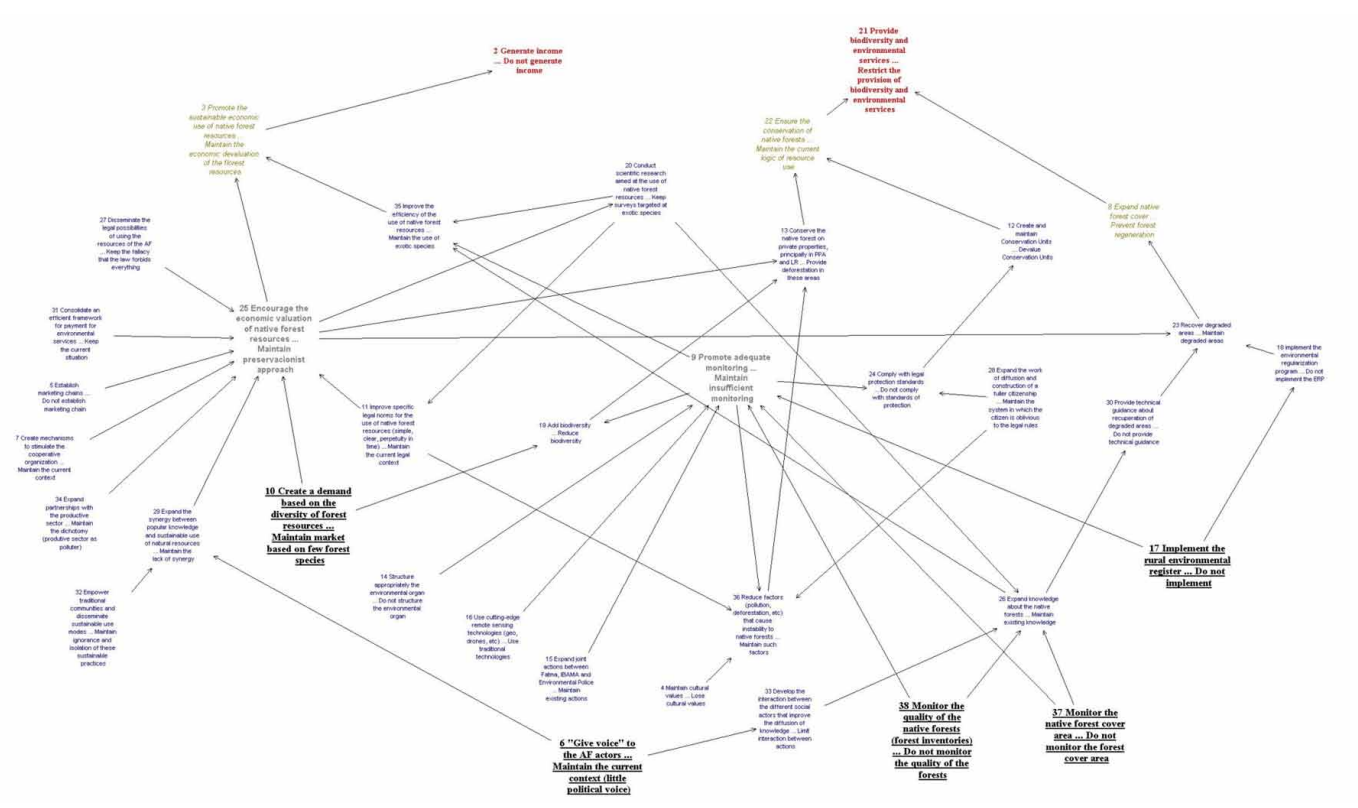

determined. In the problem situation of the native forests of Santa Catarina - Brazil, the meaning of the constructs evidenced by the analyses of the causal map was investigated, finding, whenever possible, to assign units to them. Then, the logical sequence of relations between the created variables from the constructs (seeking to maintain head constructs as endogenous variables) was verified, allocating them within a Bull's Eye diagram (Figure 13).

It should be noted that cotail and potent constructs were not included in this diagram due to the impossibility of transforming them into quantitative variables or representing them in a system dynamics structure. However, they can provide qualitative information regarding the problem situation, as well as supporting the discussion of the simulation done by the model.

According to the Bull's Eye diagram in Figure 13, the system to be modelled should systematically group the following elements: the attribution of monetary value to the native forest resources (construct 26) and the consequent income generation (construct 2), the adequate monitoring of forest cover (construct 9), the sustainable use of native forest resources (construct 3), the maintenance of biodiversity (construct 21), the provision of environmental services (construct 21), and the ecological succession process (constructs 8 and 22), since it can provide both the conservation of native forests and the expansion of their areas.

\section{FINAL CONSIDERATIONS}

The great success in carrying out step 1 of the system dynamics modelling process based on the multimethodology proposed in this paper is the inclusion of different perspectives on the problem situation that is modelled. Thus, a modelling process becomes more participatory, without the need of face-to-face Group Model Building sections.

Concerning the modelled problem situation about the native forests of Santa Catarina, the proposed multimethodology ensured the inclusion of different perspectives on the model, also guaranteeing the representation of the complexity of the ecological, economic and cultural relations that drive the native forests of Santa Catarina. Then, the created system dynamics model were able 
Figure 13. Bull's Eye diagram resulting from the multimethodology described in this paper, which presents and classifies, into endogenous and exogenous, the constructs that can be used in the system dynamic modelling process for the problem situation about native forests of Santa Catarina State, Brazil.

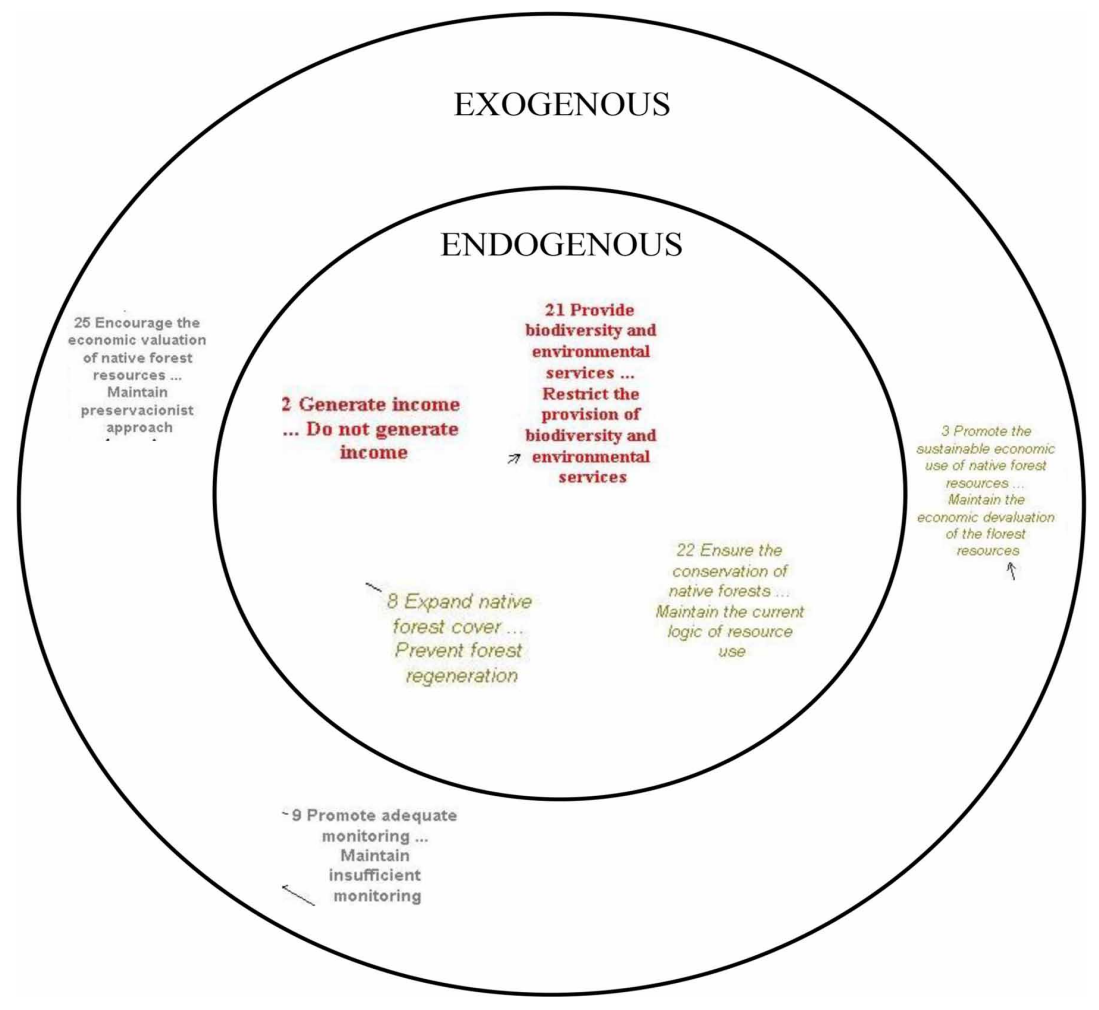

to support the establishment of more comprehensive forest policies, which that take into account different stakeholders' perspectives

Another interesting element is the use of hierarchical causal maps for the establishment of system dynamics structures. This use opens new possibilities for the construction of system dynamics models non-exclusive based on cognitive/causal maps with feedback loops.

The proposed multimethodology provides the possibility of creating scenarios, resulting from simulations of the model, based on the sensitivity analysis of the variables coming from tail constructs (which are exogenous variables of the model). This multi-methodology also makes possible linking numerical changes in the inputs of the model with actions represented by the tails of the cognitive causal map that originated the system dynamics model. 


\section{REFERENCES}

Abdollahi, H., \& Ebrahimi, S. B. (2019). Modelling and Investigating the Economy and Production Structure of Iran Public Theater: A System Dynamics Approach. International Journal of System Dynamics Applications, 8(1), 60-78. doi:10.4018/IJSDA.2019010104

Ackermann, F., \& Eden, C. (2010). Strategic Options Development and Analysis. Systems Approaches to managing change: a practical guide. doi:10.1007/978-1-84882-809-4_4

Ackermann, F., \& Eden, C. (2011). Strategic management of stakeholders: Theory and practice. Long Range Planning, 44(3), 179-196. doi:10.1016/j.lrp.2010.08.001

Ackermann, F., Eden, C., \& Williams, T. (1997). Modelling for litigation: Mixing qualitative and quantitative approaches. Interfaces, 27(2), 48-65. doi:10.1287/inte.27.2.48

Anderson, V., \& Johnson, L. (1997). Systems thinking basics. Pegasus Communications.

Antoun Netto, S. O. (2012). O uso de Multimetodologia para a determinação de Metas e Indicadores de Desenvolvimento Municipal na Área da Saúde. Rio de Janeiro: UFRJ/COPPE.

Aslani, A., Akbari, S., \& Tabasi, S. (2018). The Robustness of Natural Gas Energy Supply: System Dynamics Modelling. International Journal of System Dynamics Applications, 7(3), 57-71. doi:10.4018/IJSDA.2018070103

Banxia Software Ltd. (2017). Decision explorer® user's guide version 3.5.0. United Kington.

Brazilian Institute of Geography and Statistic (IBGE). (2016). Mapas (Base Cartográfica). Retrieved July 14, 2016, from https://mapas.ibge.gov.br/bases-e-referenciais/bases-cartograficas/malhas-digitais.html

Eden, C. (1994) Cognitive mapping and problem structuring for system dynamics model building. System Dynamics Review, 10(2,3).

Eden, C. (2004). Analysing cognitive maps to help structure issues or problems. European Journal of Operational Research, 159(3), 673-686. doi:10.1016/S0377-2217(03)00431-4

Eden, C., \& Ackermann, F. (2001). SODA the principles. In J. Rosenhead \& J. Mingers (Eds.), Rational Analysis for a Problematic World Revisited (2e). Academic Press.

Eden, C., \& Ackermann, F. (2013). Making strategy: the journey of strategic management. Academic Press.

Ford, A. (1999). Modelling the environment: an introduction to system dynamics models of environmental systems. Island press.

Georgiou, I. (2011). Cognitive mapping and strategic options development and analysis (SODA). In J. Cochran (Ed.), Wiley Encyclopedia of Operations Research and Management Science (Vol. 2). doi:10.1002/9780470400531. eorms0974

Georgiou, I. (2012). Messing about in transformations: Structured systemic planning for systemic solutions to systemic problems. European Journal of Operational Research, 223(2), 392-406. doi:10.1016/j.ejor.2012.06.010

Haddad, M., \& Otayek, R. (2019). Assessing the Sustainment of a Lean Implementation Using System Dynamics Modelling: A Case Study of Apparel Manufacturing in Lebanon. International Journal of System Dynamics Applications, 8(4), 14-29. doi:10.4018/IJSDA.2019100102

Hjorts $\emptyset$, C. N. (2004). Enhancing public participation in natural resource management using soft OR - an application of strategic option development and analysis in tactical forest planning. European Journal of Operational Research, 152(3), 667-683. doi:10.1016/S0377-2217(03)00065-1

Howick, S., \& Ackermann, F. (2011). Mixing OR methods in practice: Past, present and future directions. European Journal of Operational Research, 215(3), 503-511. doi:10.1016/j.ejor.2011.03.013

Howick, S., Eden, C., Ackermann, F., \& Williams, T. (2008). Building confidence in models for multiple audiences: The modelling cascade. European Journal of Operational Research, 186(3), 1068-1083. doi:10.1016/j. ejor.2007.02.027

Kelly, G. A. (1955). The psychology of personal constructs. Academic Press. 
Kizito, A., \& Semwanga, A. R. (2020). Modelling the Complexity of Road Accidents Prevention: A System Dynamics Approach. International Journal of System Dynamics Applications, 9(2), 24-41. doi:10.4018/ IJSDA.2020040102

Meadows, D. H. (2008). Thinking in systems: A primer. Chelsea Green Publishing.

Mingers, J. (2009). Multimethodology - mixing and matching methods. In J. Rosenhead \& J. Mingers (Eds.), Rational analysis for a problematic world revisited (pp. 289-310). John Wiley e Sons, Ltd.

Mingers, J. (2010). Multimethodology. In J. Cochran (Ed.), Wiley Encyclopaedia of Operations Research and Management Science. Wiley.

Mingers, J., \& Brocklesby, J. (1997). Multimethodology: Towards a framework for mixing methodologies. Omega. International Journal of Management Sciences, 25(5), 489-509. doi:10.1016/S0305-0483(97)00018-2

Mingers, J., \& Rosenhead, J. (2004). Problem structuring methods in action. European Journal of Operational Research, 152(3), 530-554. doi:10.1016/S0377-2217(03)00056-0

Moran-Ellis, J., Alexander, V., Cronin, A., Dickinson, M., Fielding, J., Sleney, J., \& Thomas, H. (2006). Triangulation and Integration: Processes, claims and implications. Qualitative Research, 6(1), 43-59. doi: $10.1177 / 1468794106058870$

Omamo, A. O., Rodriguez, A. J., \& Muliaro, J. W. (2018). A Systems Dynamics Model for Mobile Industry Governance in the Context of the Kenyan Vision 2030. International Journal of System Dynamics Applications, 7(2), 81-100. doi:10.4018/IJSDA.2018040105

Santos, L. D., Schlindwein, S. L., Fantini, A. C., Belderrain, M. C. N., Montibeller, G., \& Franco, L. A. (2019). Structuring contrasting forest stakeholders' views with the Strategic Options Development and Analysis (SODA) approach. International Forestry Review, 21(4), 501-515. doi:10.1505/146554819827906834

Santos, N. T., Santos, G. T., Silva, W. S., \& Ferreira, W. R. (2020). A System Dynamics Model for Sales and Operations Planning: An Integrated Analysis for the Lime Industry. International Journal of System Dynamics Applications, 9(1), 1-17. doi:10.4018/IJSDA.2020010101

Siminski, A. (2009). The forest of the future: knowledge, valuation and perspectives for the use of secondary forest formations in the state of Santa Catarina. Academic Press.

Sterman, J. D. (2000). Business Dynamics: Systems Thinking and Modelling for a Complex World. McGraw-Hill.

Vennix, J. A. (1996). Group model building facilitating team learning using system dynamics. Academic Press.

Williams, T., Eden, C., Ackermann, F., \& Tait, A. (1995). The effects of design changes and delays on project costs. The Journal of the Operational Research Society, 46(7), 809-818. doi:10.1057/jors.1995.114

Zelinka, D., \& Amadei, B. (2019). Systems Approach for Modelling Interactions Among the Sustainable Development Goals Part 1: Cross-Impact Network Analysis. International Journal of System Dynamics Applications, 8(1), 23-40. doi:10.4018/IJSDA.2019010102

\section{ENDNOTE}

This map was obtained by aggregating the individual cognitive maps.

Sandro Luis Schlindwein is a Professor at the Department of Rural Engineering of the Federal University of Santa Catarina, in Florianópolis, Brazil. He teaches Systems Thinking and Practice in the Postgraduate Programme in Agroecosystems, and supervises MSc and PhD students. He is a member of the Board of Directors of the World Organization of Systems and Cybernetics (WOSC), and his current research interests are related to the dynamics of land use change, adaptation to climate emergency and systems thinking applied to wicked situations. 